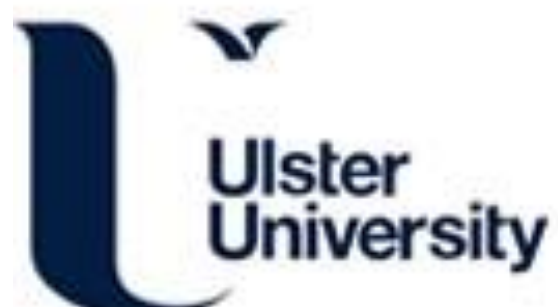

\section{Development and validation of an inventory to assess conflict in sport teams: the Group Conflict Questionnaire}

Paradis, K., Carron, A., \& Martin, L. (2014). Development and validation of an inventory to assess conflict in sport teams: the Group Conflict Questionnaire. Journal of Sports Sciences, 32(20), 1966-1978.

https://doi.org/10.1080/02640414.2014.970220

Link to publication record in Ulster University Research Portal

Published in:

Journal of Sports Sciences

Publication Status:

Published (in print/issue): 14/12/2014

DOI:

10.1080/02640414.2014.970220

\section{Document Version}

Author Accepted version

\section{General rights}

Copyright for the publications made accessible via Ulster University's Research Portal is retained by the author(s) and / or other copyright owners and it is a condition of accessing these publications that users recognise and abide by the legal requirements associated with these rights.

\section{Take down policy}

The Research Portal is Ulster University's institutional repository that provides access to Ulster's research outputs. Every effort has been made to ensure that content in the Research Portal does not infringe any person's rights, or applicable UK laws. If you discover content in the Research Portal that you believe breaches copyright or violates any law, please contact pure-support@ulster.ac.uk. 
1

2

3

4

5

6

7

8

9 Development and Validation of an Inventory to Assess Conflict in Sport Teams:

10 The Group Conflict Questionnaire

11

12

13

14

15

16

17

18

19

20

21

22

23 


\section{Abstract}

2 The purpose of the study was to develop and validate a conceptually and psychometrically sound

3 conflict questionnaire for sport. The development process involved three phases: (a) a qualitative

4 phase, (b) a content and factorial validity phase, and (c) a construct validity phase. A total of 50

5 items were generated and sent to six experts to determine content validity. Through this process,

625 items were retained and administered to a sample of athletes $(n=437)$ to determine factorial

7 validity. Based on these results, a second sample $(n=305)$ was administered the 14 -item version

8 of the Group Conflict Questionnaire (GCQ) along with the Group Environment Questionnaire

9 (Carron et al., 1985), the Athlete Satisfaction Questionnaire (Riemer \& Chelladurai, 1998), and

10 the Passion Scale (Vallerand et al., 2003) to test convergent, discriminant, and known-group

11 difference validity. Cross validation from both samples via Confirmatory Factor Analysis (CFA)

12 yielded moderate to acceptable model fit, thus supporting factorial validity for the 14-item

13 version. Additionally, initial support for convergent validity and known-group difference validity

14 and partial support for discriminant validity were found. A sport specific conflict questionnaire is

15 now available for researchers to utilise. Results and research implications are discussed.

16 Keywords: intra-group conflict, group dynamics, measurement, validity, psychometrics 
Development and Validation of an Inventory to Assess Conflict in Sport Teams: The Group Conflict Questionnaire

Conflict, defined as "a dynamic process that occurs between interdependent parties as they experience negative emotional reactions to perceived disagreements and interference with the attainment of their goals" (Barki \& Hartwick, 2004, p. 234), has been widely reported in a variety of settings (e.g., Barki \& Hartwick, 2004; Deutsch, 1990; Jehn, 1995). In the sport context, however-with a few recent exceptions (e.g., Holt, Knight, \& Zukiwski, 2012; Mellalieu, Shearer, \& Shearer, 2013; Sullivan \& Feltz, 2001) — the investigation of conflict has been sparse and underdeveloped (Martin, Bruner, Eys, \& Spink, 2014; Martin \& Beauchamp, 2014). Specifically, Lavoi (2007) noted that searches of subject indexes in various sport psychology texts failed to yield the term conflict.

Due to the limited research available in sport, literature from other domains (i.e., organizational psychology) can be utilized to grasp a better understanding of the construct. A considerable portion of this literature can be attributed to (or has been influenced by) the work of Karen Jehn and her colleagues (e.g., Jehn, 1995; 1997; Jehn \& Mannix, 2001). Jehn (1995) advanced a conceptual model of conflict that was formulated on the notion that three distinct but related types of intra-group conflict exist: task, relationship, and process conflict. According to Jehn (1997), task conflict exists when disagreements among group members occur in relation to the content of tasks being performed including differences in viewpoints, ideas, and opinions. Relationship conflict exists when interpersonal incompatibilities are present among group members. Finally, process conflict is present when disagreements arise in regard to the manner in which tasks should be delegated and performed. This conceptualization provided a foundation 
1 for understanding the nature of conflict and served as a catalyst for further research (e.g.,

2 Bendersky et al., 2010).

In relation to subsequent work based on this conceptualization, two general issues have

4 immerged. First, insofar as the conceptual framework is concerned, researchers have identified a

5 lack of empirical distinction between process and task conflict (Behfar, Mannix, Peterson, \&

6 Trochim, 2011). In recognizing this limitation, Bendersky et al. (2010) revisited the original

7 framework and combined the process and task conflict dimensions, thus resulting in two general

8 dimensions — task (e.g., divergent, convergent, and logistical coordination conflicts) and

9 interpersonal (e.g., status, compatibility, and commitment conflicts).

The second issue relates to the definition and nature of conflict. Specifically Jehn (1995;

11 1997) and other colleagues have adopted the term disagreement to describe conflict to the point

12 of perceiving (either intentionally or unintentionally) disagreement to be synonymous with

13 conflict. Although disagreement may certainly be at the root of conflict, it is possible to have

14 disagreement without necessarily having conflict. For example, individuals in a conversation

15 may disagree with regard to political or religious issues or beliefs but are not necessarily in

16 conflict with one another. In fact, recent research supports the tenet that conflict is too strong a

17 word to describe mere disagreements or differences of opinion (Hamm-Kerwin, Doherty, \&

18 Harman, 2011). Consequently, perceiving conflict to be synonymous with disagreement severely

19 risks the underrepresentation of the construct.

In line with the previous issues, Barki and Hartwick (2004) identified a lack of clear

21 conceptualization and operationalization across the literature for intra-group conflict, which they

22 highlighted as a hindrance to the comparison of previous results as well as the advancement of

23 the field. Subsequently, they advanced a more recent conceptualization that incorporates the two 
1 dimensions of task and social, but more importantly, enables the classification of conflict over

2 and above that of disagreements. Therefore, in order for a situation to be categorized as inter-

3 personal conflict, three components (cognitive, behavioural, and affective) must be present. In

4 this regard, disagreement is represented as the cognitive component, interference with goal

5 attainment as the behavioral component, and negative emotion as the affective component.

6 Accordingly, Barki and Hartwick (2004) consider conflict to exist when disagreements, negative

7 emotions, and interference behaviors are concurrently present in an inter-personal situation (i.e.,

8 between 2 or more people) based on either task or relationship (i.e., social) processes.

9 In considering that the Barki and Hartwick (2004) conceptualization allows for the proper classification or identification of inter-personal conflict, it was adopted as a theoretical guide for

11 the present study. In terms of group conflict, this generally manifests itself in two ways: between

12 opposing groups (i.e., inter-group conflict) or between members within a group (i.e., intragroup

13 conflict) (Martin et al., 2014). Similarly, for the purposes of this manuscript, the terms inter-

14 personal and intra-group conflict are used interchangeably herein. Essentially, the extent

15 literature in the sport setting (e.g., Holt et al., 2012; Mellalieu et al., 2013; Sullivan \& Feltz,

16 2001) has used these terms, in addition to the general use of 'conflict,' synonymously. Therefore,

17 our use of intra-group conflict throughout refers to inter-personal conflict situations between two

18 or more persons who are members of the same group/team (i.e., intra-group conflict).

As indicated above, the literature with regard to intra-group conflict in sport is sparse.

20 This is surprising considering its inevitability in any group context (Robbins \& Judge, 2010), as

21 indicated by the following quote, "I'm only certain of three things in life - death, taxes, and

22 conflict" (quoted in Lavoi, 2007, p. 34). Consistent with this suggestion, and due to its

23 interdependent and competitive nature, sport provides another platform for the investigation of 
1 intra-group conflict. One potential explanation for the lack of sustained investigation is the

2 availability of a validated measurement tool. In their recent text, Tenenbaum, Eklund, and

3 Kamata (2012) highlighted the importance of questionnaire development by stating,

4 "measurement is essential to science, it must be trustworthy, and accurate" (p. 3). Similarly,

5 questionnaire development is fundamental to the advancement of knowledge (Carron, Eys, \&

6 Martin, 2012). Therefore, the purpose of the present study was to develop and validate a sport

7 specific conflict questionnaire - The Group Conflict Questionnaire (GCQ). The GCQ was

8 developed using a common multi-phase approach to questionnaire development (e.g., Carron,

9 Widmeyer, \& Brawley, 1985; Eys, Loughead, Bray, \& Carron, 2009; Martin, Carron, Eys, \&

10 Loughead, 2012).

11 Specifically, our approach encompassed three phases (a qualitative phase, a questionnaire

12 development and structural validity phase, and a construct validity phase), which are described in

13 greater detail in the methods section. Phase 1 involved an exploratory qualitative investigation in

14 which athletes served as active agents to help gain a better understanding of how they perceived

15 the nature of intra-group conflict in sport. This phase involved in the consideration of participant

16 responses in combination with a more thorough literature review, and definition and conceptual

17 model (e.g., Barki \& Hartwick, 2004) for the formulation of an initial item pool in Phase 2.

18 With regard to Phase 2, two sequential stages were undertaken. First, potential items for

19 the GCQ were developed and six researchers with expertise in group dynamics in the context of

20 sport were recruited to assess their content validity. These experts were asked to determine the

21 extent to which the items represented (a) intra-group conflict in sport generally and (b) the

22 proposed conceptual model specifically. Second, factorial validity of the preliminary

23 questionnaire was assessed via Confirmatory Factor Analysis (CFA). This analysis yielded a 14- 
1 item (7-task and 7-social) inventory that measures perceptions of intra-group conflict on a 9-

2 point Likert-type scale. Consistent with the conceptual model (i.e., Barki \& Hartwick, 2004),

3 each item made reference to (a) disagreements (i.e., cognitive), (b) negative emotions (i.e.,

4 affective), and (c) interference behaviors (i.e., behavioral). Further, items were developed for

5 both task and social situations, which has been supported in the sport literature (e.g., Holt et al.,

6 2012; Paradis, Carron, \& Martin, in press).

7 In recognition of the fact that validity testing is an ongoing process (e.g., Carron et al.,

8 1985), it was necessary to conduct further assessment to determine the construct validity of the

9 GCQ. Thus, Phase 3 involved the assessment of factorial, convergent, discriminant, and known-

10 group difference validity (e.g., Brawley, Carron, \& Widmeyer, 1987; Martin, Carron, Eys, \&

11 Loughead, 2013). Each assessment of validity is subsequently described in greater detail.

The first type of validity tested was factorial validity, demonstrated through the model fit

13 and factor loadings obtained from a CFA. A common practice in validity testing is to perform

14 cross validation studies with independent samples whenever possible (Tabachnick \& Fidell,

15 2013). As such, this second factorial validity test would be used to complement the one

16 undertaken during Phase 2 with a different sport sample. Providing additional evidence of

17 factorial validity would further support the construct validity of the GCQ.

18 The demonstration of convergent validity occurs when constructs that are theoretically

19 related, are in fact shown to be related (e.g., Smith, Cumming, \& Smoll, 2008). One construct in

20 organizational settings that has been consistently related (albeit negatively) to intra-group

21 conflict is satisfaction (e.g., De Dreu \& Van Vianen, 2001; De Dreu \& Weingart, 2003).

22 Therefore, for the present study, it was hypothesised that task and social conflict would be

23 negatively related to satisfaction in a sport setting. 
Another construct used to assess convergent validity was cohesion, defined as "a dynamic process that is reflected in the tendency for a group to stick together and remain united in the pursuit of its instrumental objectives and/or for the satisfaction of member affective needs" (Carron, Brawley, \& Widmeyer, 1998, p. 213). Cohesion plays an important role in the functioning and effectiveness of all groups (e.g., Carron et al., 1985). In fact, Sullivan and Feltz (2001) suggested conflict may be the antithesis of cohesion, thus demonstrating a negative relationship. In line with this suggestion, it was hypothesized that task and social conflict would be negatively related to task and social cohesion.

Discriminant validity is demonstrated when theoretically plausible differences do in fact emerge between constructs (e.g., Smith et al., 2008). The construct used to test this type of validity in the present study was passion, defined as "a strong inclination toward an activity that people like, that they find important, and in which they invest time and energy" (Vallerand et al., 2003, p. 757). The Dualistic Model of Passion consists of harmonious passion which "results from an autonomous internalization of the activity into the person's identity" and obsessive passion which "results from a controlled internalization of the activity into one's identity" (Vallerand et al., 2003, p. 757). Previous research has shown that negative emotions (also a component of intra-group conflict) were positively related to obsessive passion and negatively related to the quality of interpersonal relationships and interpersonal connectedness, whereas a negative relationship was demonstrated between negative emotions and harmonious passion (Phillipe, Vallerand, Houlfort, Lavigne, \& Donohue, 2010). That is, more positive emotions were experienced in inter-personal relationships by those who were harmoniously passionate compared to those who were obsessively passionate. On the basis of these findings, it was expected that task and social conflict would share different relationships with harmonious and 
1 obsessive passion - namely, that intra-group conflict (task and social) would be inversely related

2 to harmonious passion but positively related to obsessive passion.

Finally, known-group difference is demonstrated when populations that are theoretically

4 hypothesized to differ are in fact shown to have mean differences pertaining to the target variable

5 (Rowe \& Mahar, 2006). One common method of assessing known-group difference is with sport

6 type (i.e., individual vs. team sport; Brawley et al., 1987; Martin et al., 2013). Martin et al.

7 (2013) found that athletes participating in team sports perceived greater perceptions of cohesion

8 than those participating in individual sports. Based on these results, it was hypothesized that

9 team sport athletes would experience less social conflict than those in individual sports.

10

11
However, we felt the same hypothesis was not tenable for task conflict. That is, individual sport athletes logically should experience little to no task conflict since their tasks are carried out independently. Likewise, given the fact that team sport athletes must work together to carry out their tasks, it would seem more logical that they would experience greater task conflict.

However, given the collective mindset of team sport vs. the individualistic mindset of individual sport, greater social conflict might be expected in individual sport contexts. Thus, it was hypothesized that team sport athletes would experience greater task and less social conflict than their individual sport counterparts.

The second known-group difference test involved team tenure (e.g., Brawley et al., 1987; Martin et al., 2013) as the differentiating variable. Player turnover, from year to year requires new team members to join the group and have an adjustment period in which they try to fit in, adapt to the culture and norms, compete for positions, and demonstrate their worth at the start of each new season. As suggested by Tuckman (1965), this storming phase in group development often leads to conflict situations. Likewise, veteran athletes are typically comfortable in their 
1 roles and positions on the team, abide by team norms, and are familiar with the team culture.

2 Thus, it was hypothesized that athletes with less team tenure would report higher perceptions of

3 task and social intra-group conflict.

\section{Method}

\section{Procedure}

Ethical approval was obtained from the lead author's institution Research Ethics Board to

7 conduct the qualitative study (i.e., Phase 1) and the questionnaire development and validation

8 (i.e., Phases 2 and 3). The following provides an outline of these phases.

\section{Phase 1: Qualitative Assessment of Athlete Perceptions of Conflict in Sport}

A comprehensive discussion of the rationale and research associated with Phase 1 has

11 been provided elsewhere (Paradis et al., in press) and is not repeated here. As a brief summary

12 however, Phase 1 was an exploratory project used to gain an understanding of athlete perceptions

13 of intra-group conflict in sport. Specifically, it involved semi-structured interviews with 10

14 intercollegiate athletes (five males and five females) who participated in a number of different

15 sports (e.g., ice hockey, track and field, rugby, volleyball, lacrosse, rowing, golf, curling,

16 competitive team dance). Before any form of measurement development could be discussed, it

17 was necessary to obtain a better understanding of intra-group conflict in the context of sport, and

18 to determine the applicability of the Barki and Hartwick (2004) conceptualization. The results

19 from this project (specifically referred to as Phase 1) identified the presence of (1) intra-group

20 conflict in sport, generally, and (2) both task and social dimensions that contained cognitive (i.e.,

21 disagreement), behavioral (i.e., goal interference), and affective (i.e., negative emotions)

22 components, specifically. In addition to providing a greater understanding of what athletes 
1 perceived intra-group conflict to be, this phase enabled the generation of items discussed in

2 subsequent sections.

\section{Phase 2: Item Generation, Content Validity, and Factorial Validity}

4 Item generation. The first objective of Phase 2 was to develop items for the

5 questionnaire. Care was taken to assess the information obtained by athletes in Phase 1, as

6 participant responses represent a rich source of content valid perceptions for the nature of any

7 construct (Carron et al., 1985). As indicated, results from the qualitative portion coupled with our

8 knowledge of the literature were taken into consideration to generate 50 items reflecting task

$9(n=25)$ and social $(n=25)$ intra-group conflict. Each of those items contained a reference to a

disagreement, affect, and behavioral interference.

Generally, in test development, it is important that items do not contain more than one response option (e.g., "I feel happy and energetic"). In such cases, respondents may agree with one option but not with the second, making it difficult for them to provide a valid response. However, it is equally important that each item fully represent the construct as it is defined conceptually. Thus, consistent with our constitutive definition, which was derived from Barki and Hartwick, (2004), each of our items contained reference to a cognitive, behavioral, and affective component (e.g., "Members of our team have intense [affective] disagreements [cognitive] to the point of dysfunction [behavioural]" ... "Arguments [behavioural] get very heated [affective] between teammates who have differing viewpoints [cognitive] about what should be done during competition"). Therefore, it is possible for a respondent to agree with one component within the item (e.g., a disagreement was present) but not another (e.g., there was no accompanying emotion or behaviour). In this case, the interaction would not be classified as intra-group conflict (i.e., all three components must be present). Note that, while all three 
1 components must be present, they can certainly have varying levels of intensity. Should

2 respondents find that they are unable to agree with all three components within the item, the

3 experiences they are reflecting would not represent our understanding of intra-group conflict and

$4 \quad$ would thus respond accordingly.

5 Content validity. The second objective of Phase 2 was to determine the content validity

6 (i.e., item content relevance; see Dunn, Bouffard, \& Rogers, 1999) of the proposed items. Ten

7 experts in the field of sport psychology with research interests that lie in group dynamics

8 principles were contacted and invited to take part in the item assessment. A total of six (all at the

9 Associate Professor or Professor level with their respective institutions who ranged from 10-35

10 years of experience in the field, agreed to participate, which satisfied the suggested minimum $(n$

$11=5$ ) number of expert reviewers necessary for controlling against chance agreement (Lynn,

12 1986). In order to avoid biased assessment of the items (Crocker \& Algina, 1986), the experts

13 had not been involved in any portion of the test construction nor had previously seen the items

14 and were not told of the proposed dimension (i.e., task or social). In addition, the experts were

15 given the Barki and Hartwick (2004) definition and conceptual framework.

The experts reviewed all items independently and were specifically asked to identify

17 whether an item represented task or social intra-group conflict as well as the degree to which it

18 incorporated disagreement, negative emotions, and interference behavior. The experts were also

19 asked to provide qualitative feedback with regard to each item. The purpose of the qualitative

20 feedback was to determine the basis for low ratings (e.g., "not clear if this is a task or social

21 conflict item") and potential ways in which the item could be improved or whether it should be

22 deleted. 
Responses were provided on a 5-point Likert-type scale: 1 = poor match, 2 = fair match,

23 = good match, 4 = very good match, 5 = excellent match (e.g., Dunn et al., 1999). Thus, for example, a task intra-group conflict item viewed as an excellent match would obtain a rating of 5

4 for task (and 1 for social). Conversely, an item considered to be a poor match would obtain a

5 rating of 1 for task (and 5 for social). Additionally, experts were asked to rate the degree to

6 which the items represented disagreement, negative emotions, and interference behaviors on the

7 same scale providing an overall score for each item in these categories. The combined means

8 from all expert raters were tallied and on the basis of these ratings, 25 items were removed and

925 items were retained. Specifically, 15 items $(M=3.17-4.83)$ pertaining to task and 10 items

$10(M=3.00-4.50)$ pertaining to social intra-group conflict were maintained for further analyses.

11 Any items scoring poorly in all areas were deleted, likewise, items had to obtain a minimum

12 score of 3 to be obtained for further analyses.

13 Factorial Validity. The third objective of Phase 2 was to utilise the content valid items in 14 an assessment of factorial validity via CFA.

\section{Participants}

Demographic information was collected from 437 ( $n=230$ females, $n=207$ males)

17 participants with a mean age of $18.61(S D=1.51)$ years who had an average experience of 7.86

$18(S D=4.32)$ years in their respective sport and an average tenure of $3.11(S D=2.35)$ years on

19 their respective team. Participants self-identified their competition level $(n=305$ competitive, $n$ $20=132$ recreational), starting status ( $n=362$ starters, $n=75$ non-starters $)$, and sport type. A total

21 of thirty different sports were identified by participants, with the most common being soccer $(n=$

22 91), ice hockey $(n=61)$, basketball $(n=49)$, American football $(n=34)$, volleyball $(n=27)$,

23 baseball/softball $(n=19)$, rugby $(n=17)$, swimming $(n=14)$, and track and field $(n=13)$. 


\section{Measures}

Conflict. As indicated above, two dimensions of conflict were assessed: task (e.g., "The team's ability to be successful is jeopardized [behavioural] because of heated [affective] disagreements [cognitive] during competition") and social (e.g., "Emotions [affective] run high in social situations over personal disagreements [cognitive] brought [behavioural] to light"), all of which had references to a cognition (such as disagreement), a negative affective emotion (such as anger), and behavioral action (such as sabotage). Reponses were provided on a 9-point Likert-type scale anchored at 1 (strongly disagree) and 9 (strongly agree). Thus higher scores reflected stronger perceptions of intra-group conflict.

\section{Analysis}

A CFA using maximum likelihood estimation was conducted via Amos 20.0 (Arbuckle, 2011) based on a two-factor model of task and social intra-group conflict. The rationale for the utilisation of a CFA as opposed to an EFA stemmed from the combination of several indicators suggesting that there was both a theoretical and empirical basis to do so. First, A CFA is a confirmatory technique that is theory driven (Schreiber, Stage, King, Nora, \& Barlow, 2006) and in which the researcher has an a priori specified theoretical model (Schumacher \& Lomax, 2010) whereas for an EFA the researcher does not have such a model. Likewise, as Kline (2005) highlights "It is not entirely appropriate to specify a CFA model based on the results of an Exploratory Factor Analysis (EFA) and to estimate the former using the same data" (p. 204). As indicated previously, the Barki and Hartwick (2004) conceptualization served as the underlying theoretical model for our work and therefore contributed to our decision to use CFA.

Assessing model fit was done through the examination of various fit indices including the Comparative Fit Index (CFI; Bentler, 1990), the Root Mean Square Error of Approximation 
1 (RMSEA; Browne \& Cudeck, 1993), and the Standardized Root Mean Square Residual (SRMR;

2 Bentler, 1995). Tabachnick and Fidell (2013) noted that the most commonly reported fit indices

3 have been the CFI and the RMSEA. Also, Hu and Bentler (1999) have suggested the CFI and the

4 SRMR are the most important indices for reporting model fit. For the CFI, values greater than

5.90 represent good fit (e.g., Bentler, 1990) whereas values greater than .95 represent excellent fit

6 (e.g., Hu \& Bentler, 1999). For the RMSEA, values less than .08 indicate excellent fit whereas

7 values less than .10 indicate moderate fit (e.g., Browne \& Cudeck, 1993; MacCallum, Browne,

8 \& Sugawara, 1996). For the SRMR, values less than .06 represent excellent fit and values less

9 than .08 represent moderate fit (Bentler, 1995; Browne \& Cudeck, 1993; Hu \& Bentler, 1999).

\section{Phase 2 Results}

11 Descriptive Statistics

Descriptive statistics including means, standard deviations, Cronbach's alphas, bivariate

13 Pearson correlations (between the task and social dimensions), and skewness and kurtosis data

14 (for both the 25-item and the 14-item versions) are reported in Table 1.

\section{Confirmatory Factor Analysis}

Results from the CFA on the 25-item version of the questionnaire yielded statistically

17 significant fit indices but did not meet the desired cut-off values $\left(\chi^{2}(274)=1502.11, p=.00\right.$;

$18 \mathrm{CFI}=.837, \mathrm{RMSEA}=.101, \mathrm{SRMR}=.065)$. All item factor loadings (see Table 2$)$ were

significant $(p=.00)$ and ranged from .582-.845 for task and from .646-.830 for social intra-group

20 conflict. The task and social dimensions were significantly related and co-varied at $.81(\mathrm{r}=.76)$.

Post-hoc modifications were performed to find a more parsimonious and better fitting

22 model. The initial step involved eliminating items with the lowest factor loadings. Historically,

23 factor loadings above .70 are considered excellent while loadings above .60 are considered very- 
1 good (Comrey \& Lee, 1992). In this regard, considering our analysis indicated that most factor

2 loadings were very-good, the decision was made to retain 14 items with factor loadings greater

3 than .70 which resulted in 11 items being removed: eight task items (.582-.641) and three social

4 items (.646-.677). A second CFA was then conducted with the 14 remaining items.

The second CFA produced a statistically significant model with improved fit indices $\left(\chi^{2}=\right.$

6 (76), 323.07, $p=.00 ; \mathrm{CFI}=.946, \mathrm{RMSEA}=.086, \mathrm{SRMR}=.042$ ). The factor loadings of all

7 items (see Table 3) were significant $(p=.00)$ and ranged from .641-.893 for task and from .711-

8.842 for social intra-group conflict. The task and social dimensions were also significantly

9 related and co-varied at $.79(\mathrm{r}=.74)$. A chi-square difference test $\left(\Delta \chi^{2}(198)=147.01, p=.00\right)$

10 showed that the second parsimonious (nested) model was indeed significantly superior. All

11 factor loadings for the 25-item and the 14-item CFA's are found in Tables 2 and 3, respectively.

12 Finally, the inter-item correlations for the final 14-items are found in Table 4 and the

13 questionnaire items are found in Table 5 (deleted items are crossed out).

14 Phase 3: Cross Validation and Further Tests of Validity

The objective for Phase 3 was to cross-validate the results of the CFA from Phase 2 with

16 a different sample for factorial validity, while also performing additional tests of validity

17 (convergent, discriminant, and known-group difference).

18 Participants

The sample included 305 ( $n=183$ females, $n=122$ males $)$ participants with a mean age

20 of $20.79(S D=1.56)$ years, an average of $9.45(S D=4.82)$ years of experience in their respective

21 sport, and an average of $2.85(S D=2.45)$ years on their respective team. In addition, participants

22 self-identified their competition level ( $n=223$ competitive, $n=82$ recreational) and starting

23 status ( $n=260$ starters, $n=45$ non-starters). A total of thirty-three different sports were 
1 identified, with the most common being soccer $(n=52)$, ice hockey $(n=48)$, basketball $(n=36)$,

2 volleyball $(n=30)$, American Football $(n=18)$, baseball/softball $(n=17)$, track and field $(n=$

$3 \quad 17)$, rugby $(n=11)$, and swimming $(n=10)$.

\section{Measures}

Conflict. The GCQ was administered to assess perceptions of intra-group

6 conflict. The 14-item version included seven items that assessed task $(\alpha=.90$; e.g., "The

7 team's ability to be successful is jeopardized because of heated disagreements during

8 competition") and seven items that assessed social $(\alpha=.92$; e.g., "Emotions run high in

9 social situations over personal disagreements brought to light") intra-group conflict.

10 Responses were provided on a 9-point Likert-type scale anchored at 1 (Strongly

11 Disagree) and 9 (Strongly Agree). Thus, higher scores reflected greater perceptions of

12 intra-group conflict.

Cohesion. Cohesion was measured using the Group Environment Questionnaire

14 (GEQ; Carron et al., 1985). The GEQ consists of 18-items measuring four dimensions of 15 cohesion: Individual Attractions to Group-Task (ATG-T; four items, $\alpha=.76$; e.g., "I am 16 happy with the amount of playing time I get"), Individual Attractions to Group-Social

17 (ATG-S; five items, $\alpha=.85$; e.g., "Some of my best friends are on this team"), Group

18 Integration-Task (GI-T; five items, $\alpha=.81$; e.g., "Our team is united in trying to reach its 19 performance goals"), and Group Integration-Social (GI-S; four items, $\alpha=.83$; e.g., "Our 20 team would like to spend time together in the off-season”). Responses are provided on a 21 9-point Likert-type scale anchored at 1 (Strongly Disagree) and 9 (Strongly Agree).

22 Thus, higher scores represented stronger perceptions of cohesion. 
Satisfaction. Satisfaction was measured using two subscales from the Athlete

2 Satisfaction Questionnaire (ASQ; Riemer \& Chelladurai, 1998). Specifically from the

3 ASQ, three items $(\alpha=.90)$ were used to measure team integration (satisfaction by the

4 members with the contributions and coordination of their efforts towards the teams' task;

5 e.g., "How satisfied are you with team members' dedication to work together towards

6 team goals") and three items $(\alpha=.83)$ were used to measure team performance

7 (satisfaction by team members with the teams overall level of performance; e.g., "How

8 satisfied are you with the extent to which the team has met its goals for the season").

9 Responses were provided on a 7-point Likert-type scale anchored at 1 (Not at all

10 Satisfied) and 7 (Completely Satisfied). Thus, higher scores reflected greater satisfaction.

11 Passion. Passion was measured using the Passion Scale (PS; Vallerand et al.,

12 2003). The Passion Scale consists of 14-items that measure two dimensions of passion:

13 harmonious (seven items, $\alpha=.83$; e.g., "This activity is in harmony with other activities

14 in my life") and obsessive (seven items, $\alpha=.94$; e.g., "I am emotionally dependent on

15 this activity"). Responses are provided on a 7-point Likert-type scale anchored at 1 (Do

16 not Agree at all) and 7 (Completely Agree). Thus, higher scores reflected greater passion.

17 Analysis

18 Factorial validity was assessed by conducting a CFA using the maximum

19 likelihood estimation via AMOS 20.0 (Arbuckle, 2011). Convergent and discriminant

20 validity were assessed using Pearson product moment correlations (two-tailed) to

21 determine the relationships between intra-group conflict, cohesion, satisfaction, and

22 passion. Known-group difference validity was assessed using discriminant function

23 analysis to determine whether intra-group conflict (task and social) could differentiate 
1 group differences and membership between sport type (individual and team), and team

2 tenure ( $\geq 1$ year and $\leq 2$ years).

4 Descriptive Statistics

5

6 found in Table 7, inter-item correlations for the GCQ are found in Table 8, and item

7 factor loadings for the GCQ are found in Table 9.

\section{$8 \quad$ Factorial Validity}

17 validity of the GCQ.

\section{Convergent Validity} inversely) related to task and social cohesion (in both manifestations of attractions to

\section{Phase 3 Results}

A CFA was conducted with AMOS 20.0 (Arbuckle, 2011) to further assess the factorial validity of the GCQ. The CFA yielded a statistically significant model fit $\left(\chi^{2}\right.$ $(76)=348.72, p=.00 ; \mathrm{CFI}=.903, \mathrm{RMSEA}=.109, \mathrm{SRMR}=.060)$. The inter-factor correlation between the task and social dimensions was also moderate $(\varphi=.65)$ and the internal consistency values were $\alpha=.90$ for task and $\alpha=.92$ for social. The factor loadings ranged from .637-.855 for task and .671-.842 for social intra-group conflict, with the majority of factor loadings above .70 (with the exception of two items; one task item at .637 and one social item at .671). Thus, results from the CFA support the factorial

The first test of convergent validity involved the examination of the relationship between intra-group conflict (task and social) and cohesion (task and social). It was hypothesized that both dimensions of intra-group conflict would be significantly (but group and group integration). The results supported the hypotheses. Task conflict was 
1 significantly and negatively related to all four dimensions of cohesion: $A T G-T(r=-.314$,

$2 p<.01)$, GI-T $(r=-.342, p<.01), A T G-S(r=-.267, p<.01)$, and $G I-S(r=-.254, p<$

3 .01). Likewise, social conflict was also significantly and inversely related to all four

4 dimensions of cohesion: $A T G-T(r=-.201, p<.01), G I-T(r=-.282, p<.01), A T G-S(r=$

$5 \quad-.180, p<.01)$, and $G I-S(r=-.181, p<.01)$. Thus, higher perceptions of task and social

6 intra-group conflict were associated with lower levels of task and social cohesion.

7 The second test of convergent validity involved an examination of the

8 relationships between conflict (task and social) and satisfaction (team integration and

9 team performance). It was hypothesized that both types of intra-group conflict would be

10 significantly and negatively related to both measures of satisfaction. Results supported

11 the hypothesis; the task dimension was significantly and negatively related to satisfaction

12 with team integration $(r=-.373, p<.01)$ and team performance $(r=-.355, p<.01)$.

13 Likewise, the social dimension was significantly and negatively related to satisfaction

14 with team integration $(r=-.266, p<.01)$ and team performance $(r=-.276, p<.01)$.

15 Thus, higher perceptions of task and social intra-group conflict were associated with

16 lower levels of satisfaction with team integration and team performance.

\section{Discriminant Validity}

The assessment of the differences between relationships for both dimensions of

19 intra-group conflict (task and social) and passion (harmonious and obsessive) served as

20 support for discriminant validity. It was hypothesized that intra-group conflict would

21 have a significant negative relationship with harmonious passion, and a significant

22 positive relationship with obsessive passion. Likewise it was hypothesized that social

23 conflict would have a stronger relationship to obsessive passion compared to task 
1 conflict. Results provided only partial support for these hypotheses. Specifically, task $(r=$

$2-.219, p<.01)$ and social $(r=-.210, p<.01)$ intra-group conflict were both significantly

3 and inversely related with harmonious passion; however no significant relationships were

4 demonstrated with obsessive passion (task: $r=.042, p>.05$; social: $r=.070, p>.05$ ).

5 Known-Group Difference Validity

6 The first known-group difference validity test involved team tenure as the

7 grouping variable and task and social intra-group conflict as the independent variables. It

8 was hypothesized that athletes with less tenure would have greater perceptions of both

9 forms of intra-group conflict. Results supported this hypothesis (Wilks' $\lambda=.96, \chi^{2}(2)=$

$1012.55, p=.004)$. The canonical correlation was .33 and the standardized canonical

11 discriminant function coefficients were .51 (task) and 1.12 (social). The functions at

12 group centroids were .20 for $\leq 1$-year tenure and -.25 for $\geq 2$-year tenure. A total of

$1357.7 \%$ of original grouped cases were classified correctly. As indicated above, those

14 athletes with less tenure experienced more task and social conflict $(M=3.60$ and 3.19

15 respectively) than athletes with longer tenure $(M=3.18$ and 2.37 respectively).

The second known-group difference test used sport type (individual vs. team) as

17 the grouping variable and task and social intra-group conflict as the independent

18 variables. It was hypothesized that athletes participating in team sports would experience

19 more task conflict but less social conflict than athletes participating in individual sports.

20 Results provided support for the hypothesis (Wilks' $\left.\lambda=.96, \chi^{2}(2)=11.19, p=.004\right)$. The

21 canonical correlation was .20, the standardized canonical discriminant function

22 coefficients were 1.19 (task) and -1.10 (social), and the functions at group centroids were

23.10 for team sport and -.36 for individual sport. A total of $54.4 \%$ of original grouped 
1

cases were classified correctly. As hypothesized, those athletes in team sports experienced more task conflict $(M=3.43)$ than those athletes in individual sports $(M=$ 3.05), whereas those in individual sports experienced more social conflict $(M=3.11)$ than those in team sports $(M=2.83)$.

\section{Discussion}

The purpose of the present study was to develop and validate a conceptually and psychometrically sound intra-group conflict questionnaire for sport. The overall process followed previous protocols of questionnaire development in group dynamics research (e.g., Carron et al., 1985; Eys et al., 2009; Martin et al., 2012). That is, three phases were undertaken including a qualitative phase, an item generation/content and factorial validity phase, and a construct validity phase. The resulting product is the GCQ - a questionnaire that contains 14items measuring two dimensions of intra-group conflict: task and social. The first point of discussion relates to the research protocol and specifically pertains to the vigor of the questionnaire development process.

As mentioned, the process we used followed other similar protocols (e.g., Carron et al., 1985; Martin et al., 2012) as well as the recommendations from measurement experts (e.g., Dunn et al., 1999; Tenenbaum et al., 2012). A conceptual model and definition initially advanced by Barki and Hartwick (2004) were established as the starting point—“"theory provides a framework for starting a process" (Tenenbaum et al., 2012, p. 4). Another common step when developing measures is to define the construct being measured (Tenenbaum et al., 2012). The definition gave meaning to the construct in which we were interested and our qualitative investigation further supported the theory and definition of intra-group conflict that was adopted. A content validity stage - one that is often overlooked in the questionnaire development process (Dunn et 
1 al., 1999) - followed. The importance of the proper execution of this phase cannot be overstated;

2 "a typical psychological measure involves extensive literature review and expert judgment"

3 (Tenenbaum et al., 2012, p. 4). As the development of the GCQ adhered to these

4 recommendations, the content validity of the established items was supported.

With regard to the factorial validity of the GCQ, results from the initial tests were

6 promising. A proposed model is deemed to be valid when: (a) items targeting a specific factor

7 have high factor loadings and (b) the correlations between the factors are not excessively high

8 (Kline, 2011). Psychometric properties of the GCQ demonstrated initial support for the final 14-

9 item version and Cronbach's alpha (Cronbach, 1951) internal consistency scores of both

10 subscales were excellent (i.e., $. \alpha \geq .90$ ). In addition, the CFA conducted in Phase 2 produced a

11 moderate to strong inter-factor correlation $(\varphi=.74)$ between the task and social dimensions. That

12 is, the two types of intra-group conflict are moderately related - a finding that is consistent with

13 previous research (e.g., De Dreu \& Weingart, 2003). The strength of this relationship was also

14 not surprising considering it is consistent with a number of previous studies (e.g., $r=.81$; Jehn,

$15 \&$ Mannix, 2001). Furthermore, although the relationship was moderate to strong, the dimensions

16 are considered unique as it was below 90 (Kline, 2011). As for model fit, the fit indices for the

17 CFI, RMSEA, and SRMR yielded acceptable values. In terms of factor loadings, items loaded

18 strongly on the appropriate dimension exceeding .70 with the exception of one item (which was

19 above .60). Taken as a whole, our results suggest that the GCQ is an excellent representation of

20 the construct (e.g., Comrey \& Lee, 1992).

21

With regard to the CFA in Phase 3, all factor loadings with the exception of two

22 items were above .70 (rated as excellent by Comrey \& Lee, 1992) with the remaining two

23 items above 60 (rated as very good by Comrey \& Lee, 1992). The inter-factor correlation 
$1(\varphi=.65)$ was below the .90 suggested threshold, which indicated that the two dimensions

2 were related but distinct (Kline, 2011). Likewise, the fit indices for the CFI, RMSEA, and

3 SRMR indicated reasonable to adequate model fit. In this regard, these results also

4 contributed to the suggestion that the GCQ could be used with confidence to accurately

5 assess intra-group conflict in a sport context. Validity testing is however an ongoing

6 process and future research should strive to further test its validity in similar and

7 dissimilar populations.

8 In terms of convergent validity, two relationships were tested: intra-group

9 conflict-cohesion and intra-group conflict-satisfaction. Significant inverse relationships

10 were found in both analyses, providing support for convergent validity. Our results are

11 consistent with previous research (e.g., satisfaction, De Dreu \& Weingart, 2003;

12 cohesion, Sullivan \& Feltz, 2001) and were therefore not surprising. They are however

13 promising in terms of the utility of the GCQ in sport.

Another point of discussion pertains to the partial support of discriminant validity.

15 Given the significant inverse relationships between intra-group conflict (task and social)

16 and harmonious passion, it was somewhat surprising to find no significant relationships

17 with obsessive passion. Previous research has offered support for the inverse relationship

18 between harmonious passion and conflict. For example, Phillipe et al. (2010) found that

19 harmonious passion positively predicted higher quality interpersonal relationships

20 whereas obsessive passion predicted more negative emotions in these relationships. As

21 such, it would make sense that those who are harmoniously passionate within a specific

22 context experience less intra-group conflict. On the other hand, one would also surmise

23 that those who are obsessively passionate would experience greater intra-group conflict. 
A more in depth look at previous passion research may offer support for this

2

3

4

result (i.e., no relationship with obsessive passion). For example, Lafrenière, Jowett, Vallerand, Donahue, and Lorimer (2008) found harmonious passion to be positively related to high quality coach-athlete relationships whereas obsessive passion was generally unrelated to the quality of the relationship. Similarly, Lafrenière, Jowett, Vallerand, and Carbonneau (2011) found that harmonious passion indirectly predicted high quality coach-athlete relationships through autonomy supportive behaviors, whereas obsessive passion predicted controlling coaching behaviors, but did not predict the quality of the coach-athlete relationship. Based on these results, obsessive passion is often unrelated to certain group relationship variables. Interestingly however, Phillipe et al. (2010) found that negative emotions (a component of intra-group conflict) significantly mediated the link between obsessive passion and the quality of interpersonal relationships. Perhaps then, intra-group conflict may serve as a mediator to obsessive passion with factors such as relationship quality - a worthwhile endeavour for future research to investigate.

Pertaining to the known-group difference validity tests, both tests involving team tenure and sport type as the grouping variables supported the proposed hypotheses. In terms of team tenure, athletes with less tenure perceived more intra-group conflict than those with greater tenure. Results are also supported in the group development literature that suggests newcomers to a team may go through a storming stage (e.g., Tuckman, 1965), which involves adjusting to the team norms, competing for position, and establishing themselves within the team. From a practical perspective, team building interventions in early season could help manage potential intra-group conflict situations 
1 experienced during group development. Likewise coaches acknowledging the initial

2 challenges of group development process may look to ensure athlete roles are clarified

3 and team norms are outlined from the group's inception.

4 With regard to sport type, an interesting discrepancy was supported. Specifically,

5 team sport athletes perceived greater amounts of task intra-group conflict whereas

6 individual sport athletes perceived more social intra-group conflict. In team sports,

7 athletes are consistently required to strategize, plan, and work together to achieve

8 common goals. It is not surprising then, that in comparison to individual sports - where

9 athletes do not experience the same amount of interdependence-greater task conflict

10 emerges. On the other hand, individual sport athletes may not have the same

11 opportunities to form strong relationships as do team sport athletes, simply by virtue of

12 the limited amount of time spent together. As such, social conflict may be more likely to

13 arise in an individual sport if athletes aren't as familiar with teammates and are not as

14 used to interacting with each other.

Previous work supported the importance of understanding teammate preferences

16 in individual sport and how these can reduce intra-group conflict (Beauchamp, Lothian,

$17 \&$ Timson, 2008). In fact, after a team building intervention focusing on cohesion, track

18 and field athletes reported that intra-group conflict was reduced (Beauchamp et al.,

19 2008). It would seem important then for individual athletes to make efforts to get to know

20 their teammates. Building on this, the potential practical implications emanating from the

21 current research might be useful in group assessment and formation. Similar team

22 building protocols (e.g., Carron \& Spink, 1993) that are theory driven and directly target

23 intra-group conflict could be implemented, with the use of the new measure as one way 
1 to assess its effectiveness. Likewise through use of the new measure, the prevalence and

2 magnitude of conflict can be assessed, with problem areas identified and targeted for

3 intervention. Likewise, further empirical work could aim to assess conflict longitudinally,

4 test for mediational relationships, and compare and contrast the intra-group conflict

5 experiences of individual and team sport athletes.

6 Overall, in terms of known-group difference, results have provided some initial

7 support for this type of validity for the GCQ, finding significant differences in the two

8 tests conducted. With that, we can suggest some initial support of known-group

9 difference validity for the two grouping variables examined (team tenure and sport type).

10 However, these are just two of many potential grouping variables in sport and further

11 assessments of this type of validity with other group variables are warranted.

12 The development and advancement of research protocols yields new findings that

13 warrant the refinement and evolution of scientific methodological practices. The

14 development and initial validation of the GCQ has provided an opportunity to advance

15 knowledge pertaining to intra-group conflict by further examining the complex

16 relationships between conflict and other group constructs. The initial support for the

17 validity of the GCQ is promising, and as such, researchers should utilise the instrument

18 for further investigations and can be confident in the results obtained from its use. 


\section{References}

Arbuckle, J. L., (2011). Amos (20.0). Crawfordville, FL: Amos Development Corporation.

Barki, H., \& Hartwick, J. (2004). Conceptualizing the construct of interpersonal conflict. International Journal of Conflict Management, 15, 216-244. doi: http://dx.doi.org/10.1108/eb022913

Beauchamp, M. R., Lothian, J. M., \& Timson, S. E. (2008). Understanding the self and others: A personality preference-based intervention with an elite co-acting sport team. Sport and Exercise Psychology Review, 4, 4-20.

Behfar, K. J., Mannix, E. A., Peterson, R. S., \& Trochim, W. M. (2011). Conflict in small groups: The meaning and consequences of process conflict. Small Group Research, 42, 127-176. doi: http://dx.doi.org/10.1177/1046496410389194

Bendersky, C., Behfar, K., Weingart, L., Todorova, G., Bear, J., \& Jehn, K. (2010). Revisiting the dimensions of intragroup conflict: Theoretical and psychometric construct refinement. IACM Paper No.11-03. doi: http://dx.doi.org/10.2139/ssrn.1611845

Bentler, P. M. (1990). Comparative fit indices in structural equation modelling. Psychological Bulletin, 107, 238-246. doi: http://dx.doi.org/10.1037/0033-2909.107.2.238

Bentler, P. M. (1995). EQS structural equation programs manual. Enchino, CA: Multivariate Software Inc.

Brawley, L. R., Carron, A. V., \& Widmeyer, W. N. (1987). Assessing cohesion in sport teams: Validation of the Group Environment Questionnaire. Journal of Sport Psychology, 9, 275-294. 
1 Browne, M. W., \& Cudeck, R. (1993). Alternative ways of assessing model fit. In K. A. Bollen,

\& J. S. Long (Eds.), Testing structural equation models (pp. 136-162). Newbury Park, CA: Sage Publications Inc.

Carron, A. V., Brawley, L. R., \& Widmeyer, W. N. (1998). The measurement of cohesiveness in sport groups. In J. L. Duda (Ed.), Advances in sport exercise psychology measurement (pp. 213-226). Morgantown, WV: Fitness Information Technology.

Carron, A. V., \& Eys, M. A. (2012). Group dynamics in sport (4th ed.). Morgantown, WV: Fitness Information Technology.

Carron, A. V., Eys, M. A., \& Martin, L. J. (2012). Cohesion. In G. Tenenbaum, R. Eklund, \& A. Kamata (Eds.), Measurement in sport and exercise psychology (pp. 411-422). Champaign, IL: Human Kinetics.

Carron, A. V., Widmeyer, W. N., \& Brawley, L. R. (1985). The development of an instrument to assess cohesion in sport teams: The Group Environment Questionnaire. Journal of Sport Psychology, 7, 244-266.

Comery, A. L., \& Lee, H. B. (1992). A first course in factor analysis (2 ${ }^{\text {nd }}$ ed.). Hillsdale, NJ: Erlbaum.

Crocker, L., \& Algina, J. (1986). Introduction to classical and modern test theory. New York, NY: Holt, Rinehart, \& Winston.

Cronbach, L. (1951). Coefficient alpha and the internal structure of tests. Psychometrika, 16, 297-334. doi: http://dx.doi.org/10.1007/BF02310555

De Dreu, C. K. W., \& Van Vianen, A. E. M. (2001). Managing relationship conflict and the effectiveness of organizational teams. Journal of Organizational Behavior, 22, 309-328. doi: http://dx.doi.org/10.1002/job.71 
De Dreu, C. K. W., \& Weingart, L. R. (2003). Task versus relationship conflict, team performance, and team member satisfaction: A meta-analysis. Journal of Applied Psychology, 88, 741-749. doi: http://dx.doi.org/10.1037/0021-9010.88.4.741

Deutsch, M. (1990). Sixty years of conflict. International Journal of Conflict Management, 1, 237-263. doi: http://dx.doi.org/10.1108/eb022682

Dunn, G. H., Bouffard, M., \& Rogers, W. T. (1999). Assessing item content-relevance in sport psychology scale construction research: Issues and recommendations. Measurement in Physical Education and Exercise Science, 3, 15-36. doi: http://dx.doi.org/10.1207/s15327841mpee0301_2

Eys, M. A., Loughead, T. M., Bray, S. R., \& Carron, A. V. (2009). Development of a cohesion questionnaire for youth: The Youth Sport Environment Questionnaire. Journal of Sport \& Exercise Psychology, 31, 390-408.

Hamm- Kerwin, S., Doherty, A., \& Harman, A. (2011). "Its not conflict, its differences of opinion": An in-depth examination of conflict in non-profit boards. Small Group Research, 42, 562-594. doi: http://dx.doi.org/10.1177/1046496411398395

Holt, N. L., Knight, C. J., \& Zukiwski, P. (2012). Female athletes' perceptions of teammate conflict in sport: Implications for sport psychology consultants. The Sport Psychologist, $26,135-154$.

Hu, L. T., \& Bentler, P. M. (1999). Cut-off criteria for fit indexes in covariance structure analysis: Conventional criteria versus new alternatives. Structural Equation Modelling, 6, 1-55. doi: http://dx.doi.org/10.1080/10705519909540118 
1 Jehn, K. A. (1995). A multi-method examination of the benefits and detriments of intragroup conflict. Administrative Science Quarterly, 40, 256-282. doi: http://dx.doi.org/10.2307/2393638

Jehn, K. A. (1997). A qualitative analysis of conflict types and dimensions in organizational groups. Administrative Science Quarterly, 42, 530-557. doi: http://dx.doi.org/10.2307/2393737

Jehn, K. A., \& Mannix, E. A. (2001). The dynamic nature of conflict: A longitudinal study of intragroup conflict and group performance. Academy of Management Journal, 44, 238-251. doi: http://dx.doi.org/10.2307/3069453

Kline, R. B. (2011). Principles and practice of structural equation modelling (3rd ed.). New York, NY: The Guilford Press.

Lafrenière, M. A. K., Jowett, S., Vallerand, R. J., \& Carbonneau, N. (2011). Passion for coaching and the quality of the coach-athlete relationship: The mediating role of coaching behaviours. Psychology of Sport and Exercise, 12, 144-152. doi: http://dx.doi.org/10.1016/j.psychsport.2010.08.002

Lafrenière, M. A. K., Jowett, S., Vallerand, R. J., Donahue, E. G., \& Lorimer, R. (2008). Passion in sport: On the quality of the coach-athlete relationship. Journal of Sport \& Exercise Psychology, 30, 541-560.

Lavoi, N. M. (2007). Interpersonal communication and conflict in the coach-athlete relationship. In S. Jowett \& D. Lavallee (Eds.), Social psychology in sport (pp. 29-40). Champaign, IL: Human Kinetics.

Lynn, M. R. (1986). Determinations and quantification of content validity. Nursing Research, 35, 382-385. doi: http://dx.doi.org/10.1097/00006199-198611000-00017 
MacCallum, R. C., Browne, M. W., \& Sugawara, H. M. (1996). Power analysis and determination of sample size for covariance structure modelling. Psychological Methods, 1, 130-149. doi: http://dx.doi.org/10.1037/1082-989X.1.2.130

Martin, L. J., \& Beauchamp, M. R. (2014). Conflict in sport. In R. Eklund \& G. Tenenbaum (Eds.), Encyclopedia of sport and exercise psychology. Thousand Oaks, CA: Sage.

Martin, L. J., Bruner, M., Eys, M. A., \& Spink, K. (2014). The social environment in sport : Selected topics. International Review of Sport and Exercise Psychology, 7, 87-105. doi: http://dx.doi.org/10.1080/1750984X.2014.885553

Martin, L. J., Carron, A. V., Eys, M. A., \& Loughead, T. M. (2012). Development of a cohesion inventory for children's sport teams. Group Dynamics: Theory, Research, and Practice, 16, 68-79. http://dx.doi.org/10.1037/a0024691

Martin, L. J., Carron, A. V., Eys, M. A., \& Loughead, T. M. (2013). Validation of the Child Sport Cohesion Questionnaire. Measurement in Physical Education and Exercise Science, 17, 105-119. doi: http://dx.doi.org/10.1080/1091367X.2013.761023

Mellalieu, S., Shearer, D. A., \& Shearer, C. (2013). A preliminary survey of interpersonal conflict at major games and championships. The Sport Psychologist, 27, 120-129.

Paradis, K. F., Carron, A. V., \& Martin, L. J. (in press). Athlete perceptions of intra-group conflict in sport teams. Sport and Exercise Psychology Review.

Phillipe, F. L., Vallerand, R. J., Houlfort, N., Lavigne, G. L., \& Donohue, E. G. (2010). Passion for an activity and the quality of interpersonal relationships: The mediating role of emotions. Journal of Personality and Social Psychology, 98, 917-932. doi: http://dx.doi.org/10.1037/a0018017 
Riemer, H. A., \& Chelladurai, P. (1998). Development of the Athlete Satisfaction Questionnaire (ASQ). Journal of Sport \& Exercise Psychology, 20, 127-156.

Robbins, S. P., \& Judge, T. A. (2010). Organizational behaviour (14th ed.). Englewood Cliffs, NJ: Prentice Hall.

Rowe, D. A., \& Mahar, M. T. (2006). Validity. In T. M. Wood \& W. Zhu (Eds.), Measurement theory and practice in kinesiology (pp. 9-25). Champaign, IL: Human Kinetics.

Schreiber, J. B., Stage, F. K., King, J., Nora A., \& Barlow, E. A. (2006). Reporting structural equation modelling and confirmatory factor analysis results: A review. Journal of Educational Research, 99, 323-337. doi: http://dx.doi.org/10.3200/JOER.99.6.323-338

Schumacker, R. E., \& Lomax, R. G. (2010). A beginner's guide to structural equation modelling ( $3^{\text {rd }}$ ed.). New York, NY: Routledge.

Smith, R. E., Cumming, S. P., \& Smoll, F. L. (2008). Development and validation of the motivational climate scale for youth sports. Journal of Applied Sport Psychology, 20, 116-135. doi: http://dx.doi.org/10.1080/10413200701790558

Sullivan, P. J., \& Feltz, D. L. (2001). The relationship between intra-team conflict and cohesion in hockey teams. Small Group Research, 32, 342-355. doi: http://dx.doi.org/10.1177/104649640103200304

Tabachnick, B. G., \& Fidell, L. S. (2013). Using multivariate statistics (6th ed.). NJ: Pearson. Tenenbaum, G., Eklund, R. C., \& Kamata, A. (2012). Introduction to measurement in sport and exercise psychology. In G. Tenenbaum, R. Eklund, \& A. Kamata. (Eds.), Measurement in Sport and Exercise Psychology (pp. 3-7). Champaign, IL: Human Kinetics.

Tuckman, B. W. (1965). Developmental sequences in small groups. Psychological Bulletin, 63, 384-399. doi: http://dx.doi.org/10.1037/h0022100 
1 Vallerand, R. J., Blanchard, C. M., Mageau, G. A., Koestner, R., Ratelle, C., Leonard, M., Gagne., M., \& Marsolais, J. (2003). Les passions de l'âme: On obsessive and harmonious passion. Journal of Personality and Social Psychology, 85, 756-767. doi: $\underline{\text { http://dx.doi.org/10.1037/0022-3514.85.4.756 }}$ 
Table 1

Descriptive Statistics

\begin{tabular}{ccccccc}
\hline Variable & Mean & $S D$ & $\alpha$ & $R$ & Skewness & Kurtosis \\
\hline Variable & Mean & $S D$ & $\alpha$ & $R$ & Skewness & Kurtosis \\
Task Conflict & 3.68 & 1.62 & .94 & .76 & .39 & -.61 \\
Tags fenflict & 3.20 & 1.86 & .92 & .74 & .81 & -.23 \\
(7 items) & & & & & & \\
Social & 2.96 & 1.64 & .93 & .76 & .75 & -.36 \\
Coffialt & 2.90 & 1.74 & .92 & .74 & .81 & -.34 \\
(Fonflingt) & & & & & & \\
(7 items) & & & & & & \\
\hline
\end{tabular}

Note. $\mathrm{N}=437$; Conflict measured on 1-9 Scale; $\mathrm{r}$ significant at $p=.01$ 
DEVELOPMENT AND VALIDATION OF THE GROUP CONFLICT QUESTIONNAIRE 36

Table 2

Factor Loading, Means, and Standard Deviations for 25 item CFA

\begin{tabular}{|c|c|c|c|c|}
\hline Item \# & Task Conflict & Social Conflict & Mean & $\begin{array}{l}\text { Standard } \\
\text { Deviation }\end{array}$ \\
\hline 4 & .582 & & 4.17 & 2.20 \\
\hline$z$ & .591 & & 4.16 & 2.14 \\
\hline 3 & .585 & & 4.80 & 2.26 \\
\hline 4 & .644 & & 5.18 & 2.29 \\
\hline 5 & .644 & & 4.37 & 2.44 \\
\hline 6 & .630 & & 2.07 & 1.79 \\
\hline 7 & .800 & & 3.25 & 2.37 \\
\hline 8 & .802 & & 3.85 & 2.47 \\
\hline 9 & .752 & & 2.38 & 1.98 \\
\hline 10 & .834 & & 3.01 & 2.26 \\
\hline 11 & .845 & & 3.33 & 2.45 \\
\hline 12 & .559 & & 3.91 & 2.38 \\
\hline 13 & .741 & & 2.53 & 1.98 \\
\hline 14 & .608 & & 4.06 & 2.36 \\
\hline 15 & .715 & & 4.05 & 2.25 \\
\hline 16 & & .732 & 2.72 & 2.02 \\
\hline 17 & & .783 & 3.22 & 2.29 \\
\hline 18 & & .797 & 2.98 & 2.25 \\
\hline 19 & & .830 & 3.32 & 2.26 \\
\hline 20 & & .828 & 3.23 & 2.29 \\
\hline 21 & & .646 & 3.83 & 2.53 \\
\hline 22 & & .677 & 3.40 & 2.23 \\
\hline 23 & & .804 & 2.88 & 2.03 \\
\hline 24 & & 674 & 2.05 & 1.58 \\
\hline 25 & & .726 & 1.94 & 1.60 \\
\hline
\end{tabular}

Note. $\mathrm{N}=437$; Conflict measured on 1-9 Scale; All factor loadings significant at $p=.00$. 
DEVELOPMENT AND VALIDATION OF THE GROUP CONFLICT QUESTIONNAIRE 37

\section{Table 3}

Factor loadings, Means, and Standard Deviations for 14 item CFA

\begin{tabular}{lllll}
\hline Item \# & Task Conflict & Social Conflict & Mean & $\begin{array}{l}\text { Standard } \\
\text { Deviation }\end{array}$ \\
\hline 7 & & & 2.37 \\
8 & .790 & & 3.25 & 2.47 \\
9 & .805 & & 3.85 & 1.98 \\
10 & .804 & & 2.38 & 2.26 \\
11 & .893 & & 3.01 & 2.45 \\
13 & .889 & & 3.33 & 1.98 \\
15 & .737 & .747 & 2.53 & 2.25 \\
16 & .641 & .813 & 4.05 & 2.02 \\
17 & & .809 & 2.72 & 2.29 \\
18 & & .842 & 3.22 & 2.25 \\
19 & & .813 & 2.98 & 2.26 \\
20 & & .783 & 3.32 & 2.29 \\
23 & & .711 & 3.23 & 2.03 \\
25 & & 2.88 & 1.60 \\
\hline
\end{tabular}

Note. $\mathrm{N}=437$; Conflict measured on 1-9 Scale; All factor loadings significant at $p=.00$. 
DEVELOPMENT AND VALIDATION OF THE GROUP CONFLICT QUESTIONNAIRE 38

Table 4

Correlation Matrix of the final 14-item GCQ

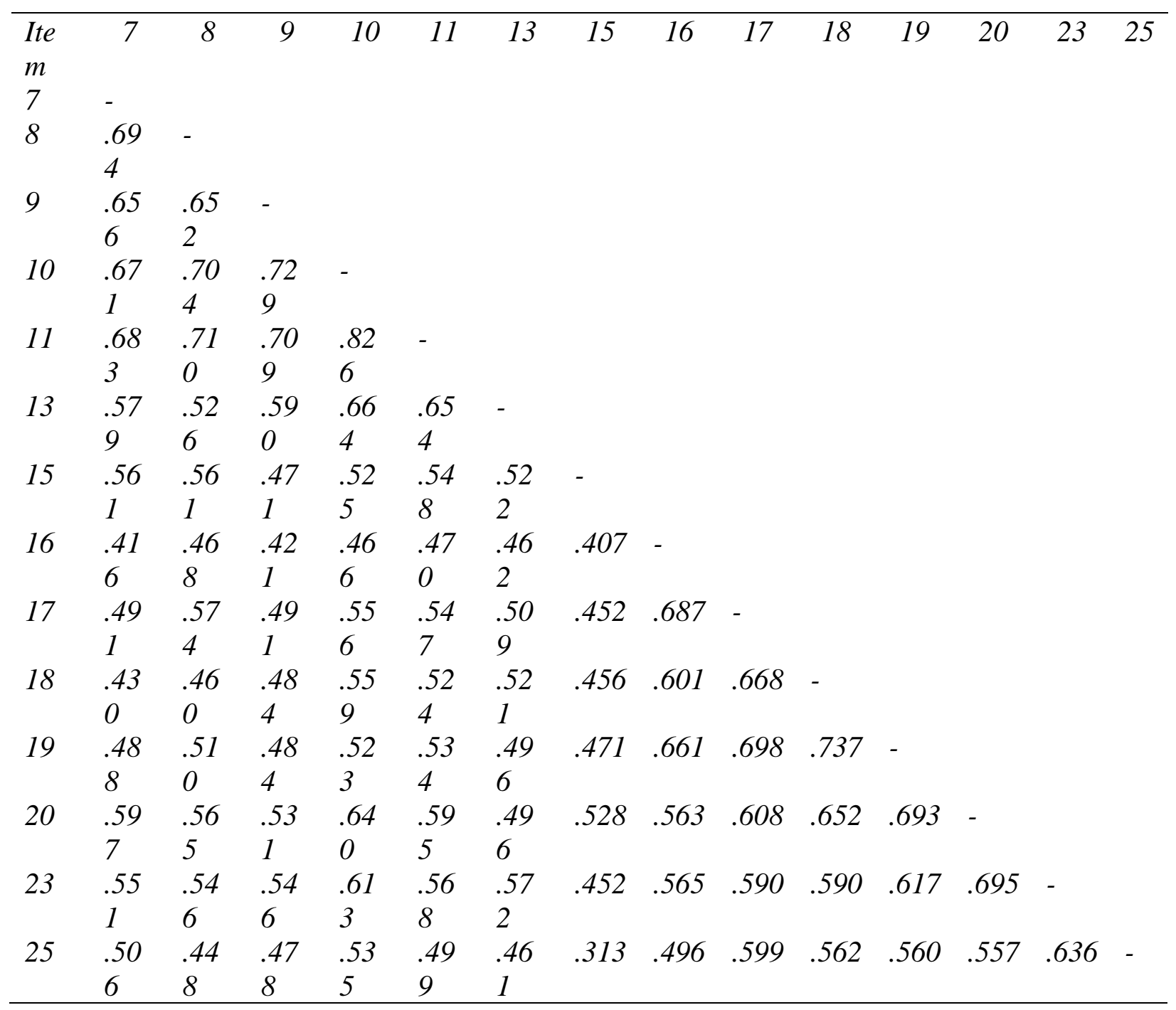

Note. $\mathrm{N}=437$; All inter-item correlations significant at $p<.01$. 
Table 5

Items in the Group Conflict Questionnaire

\section{Task Conflict Items}

1. Members of our team have heated disagreements about each other's personal commitment

2. Members of our team have emotional arguments about how to go about achieving team geals

3. Members of our team have emotional arguments in competitive situations over what's best for the team

4. Members of our team have emotional disagreements when things don't go the way they'd like

5. Arguments get very heated between teammates who have differing viewpoints about what should be done during competition

6. Members of our team sabotage each other's performance over emotional disagreements

7. The team's ability to be successful is jeopardized because of heated disagreements during competition

8. Strong disagreements during practice between members of our team disrupt our progress towards achieving team goals

9. It is nearly impossible to function effectively because of the intensity of the disagreements between members of our team during practices

10. The extreme animosity associated with the disagreements among members of our team affects our performance

11. The anger associated with the disagreements among members of our team affects our performance

12. Members of our team who are competing for the same position are often resentful of each other

13. Members of our team have intense disagreements to the point of dysfunction

14. Member of our team have emotional disagreements about their respective playing time

15. There is tension among members of our team over disagreements about performance expectations 


\section{Social Conflict Items}

16. Personal friction among members of our team leads to angry confrontations at social gatherings

17. The heated disagreements among members of our team in social situations become personal

18. Members of our team stop speaking to each other over personal disagreements in social situations

19. Emotions run high in social situations about personal differences brought to light

20. The negativity from personal disagreements makes it difficult for members of our team to be friends

21. The presence of cliques on our team leads teammates to purposely avoid each other

22. As a result of the tension surrounding disagreements, members of our team don't make an effort to get together outside of practices and competitions

23. Members of our team have negative emotional confrontations that hinder the enjoyment of social events

24. Members of our team often get into heated disfuptive arguments at team parties

25. Disagreements at social gatherings escalate quickly that damages and tears our team apart 
Table 6

Descriptive Statistics for Conflict, Cohesion, Passion, and Satisfaction

\begin{tabular}{lcclll}
\hline & Mean & SD & Skewness & Kurtosis & $\alpha$ \\
\hline $\begin{array}{l}\text { Task } \\
\text { Conflict }\end{array}$ & 3.35 & 1.64 & .47 & -.64 & .90 \\
$\begin{array}{l}\text { Social } \\
\text { Conflict }\end{array}$ & 2.90 & 1.67 & .69 & -.54 & .92 \\
$\begin{array}{l}\text { Attraction to } \\
\text { Group-Task }\end{array}$ & 7.14 & 1.37 & -1.25 & 2.02 & .76 \\
$\begin{array}{l}\text { Attraction to } \\
\text { Group-Social }\end{array}$ & 7.01 & 1.46 & -.79 & .30 & .85 \\
$\begin{array}{l}\text { Group Integration- } \\
\text { Task }\end{array}$ & 6.46 & 1.31 & -.40 & -.17 & .81 \\
$\begin{array}{l}\text { Group Integration- } \\
\text { Social }\end{array}$ & 6.15 & 1.53 & -.09 & -.74 & .83 \\
$\begin{array}{l}\text { Harmonious } \\
\text { Passion }\end{array}$ & 5.76 & .88 & -.98 & 1.31 & .83 \\
$\begin{array}{l}\text { Obsessive } \\
\text { Passion }\end{array}$ & 3.89 & 1.56 & .03 & & .94 \\
$\begin{array}{l}\text { Team } \\
\text { Integration }\end{array}$ & 5.28 & 1.09 & -1.06 & 1.20 & .90 \\
$\begin{array}{l}\text { Team } \\
\text { Performance }\end{array}$ & 5.33 & 1.12 & -1.03 & & \\
\hline$\quad$ & & & & & \\
\hline
\end{tabular}

Note. $\mathrm{N}=305$; Conflict measured on 1-9 Scale; Cohesion Measured on 1-9 scale; Passion measured on 1-7 scale; Satisfaction measured on 1-7 scale. 
Table 7

Bivariate Correlations for Conflict, Cohesion, Passion, and Satisfaction

$\begin{array}{lllllllll}1 & 2 & 3 & 4 & 5 & 6 & 7 & 8 & 9\end{array}$

1. Task

Conflict

2. Social

$.610 * * \quad-$

Conflict

3.Attraction to $\quad-.314 * * \quad-.201 * * \quad-$

Group Task

4. Attraction to $\quad-.267 * * \quad-.180 * * \quad .600 * * \quad-$

Group Social

5. Group $\quad-.342 * * \quad-.282 * * \quad .653 * * \quad .511 * * \quad-$

Integration Task

6. Group $\quad-.254 * * \quad-.181 * * \quad .458 * * \quad .755 * * \quad .608 * * \quad-$

Integration Social

$\begin{array}{lllllll}\text { 7.Harmonious } & -.219 * * & -.210^{* *} & .508 * * & .527 * * & .421 * * & .401 * *\end{array}$

Passion

$\begin{array}{lllllllll}\text { 8. Obsessive } & .042 & .070 & .148 * * & .215 * * & .130 * & .262 * * & .439 * * & -\end{array}$

Passion

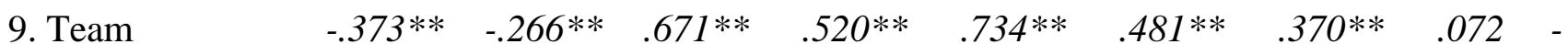

Integration

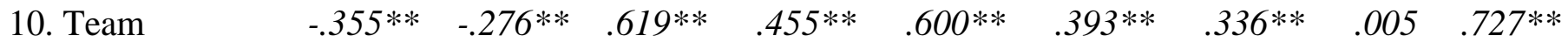

Performance

Note. $\mathrm{N}=305 ;{ }^{* *} p<.01 ; * p<.05$ 
Table 8

Inter-item correlation matrix for the GCQ

\begin{tabular}{|c|c|c|c|c|c|c|c|c|c|c|c|c|c|c|}
\hline $\begin{array}{l}\text { Ite } \\
\mathrm{m}\end{array}$ & 7 & 8 & 9 & 10 & 11 & 13 & 15 & 16 & 17 & 18 & 19 & 20 & 23 & 25 \\
\hline 7 & - & & & & & & & & & & & & & \\
\hline 8 & $\begin{array}{l}.53 \\
2\end{array}$ & - & & & & & & & & & & & & \\
\hline 9 & $\begin{array}{l}.54 \\
0\end{array}$ & $\begin{array}{l}.65 \\
1\end{array}$ & - & & & & & & & & & & & \\
\hline 10 & $\begin{array}{l}.60 \\
8\end{array}$ & $\begin{array}{l}.64 \\
3\end{array}$ & $\begin{array}{l}.71 \\
6\end{array}$ & - & & & & & & & & & & \\
\hline 11 & $\begin{array}{l}.59 \\
5\end{array}$ & $\begin{array}{l}.58 \\
1\end{array}$ & $\begin{array}{l}.55 \\
5\end{array}$ & $\begin{array}{l}.74 \\
1\end{array}$ & - & & & & & & & & & \\
\hline 13 & $\begin{array}{l}.55 \\
6\end{array}$ & $\begin{array}{l}.44 \\
7\end{array}$ & $\begin{array}{l}.54 \\
1\end{array}$ & $\begin{array}{l}.54 \\
1\end{array}$ & $\begin{array}{l}.60 \\
2\end{array}$ & - & & & & & & & & \\
\hline 15 & $\begin{array}{l}.54 \\
4\end{array}$ & $\begin{array}{l}.42 \\
6\end{array}$ & $\begin{array}{l}.41 \\
0\end{array}$ & $\begin{array}{l}.50 \\
7\end{array}$ & $\begin{array}{l}.54 \\
3\end{array}$ & $\begin{array}{l}.54 \\
5\end{array}$ & - & & & & & & & \\
\hline 16 & $\begin{array}{l}.32 \\
0\end{array}$ & $\begin{array}{l}.32 \\
4\end{array}$ & $\begin{array}{l}.48 \\
6\end{array}$ & $\begin{array}{l}.34 \\
3\end{array}$ & $\begin{array}{l}.32 \\
3\end{array}$ & $\begin{array}{l}.46 \\
1\end{array}$ & .381 & - & & & & & & \\
\hline 17 & $\begin{array}{l}.36 \\
6\end{array}$ & $\begin{array}{l}.43 \\
3\end{array}$ & $\begin{array}{l}.55 \\
1\end{array}$ & $\begin{array}{l}.41 \\
1\end{array}$ & $\begin{array}{l}.41 \\
6\end{array}$ & $\begin{array}{l}.46 \\
8\end{array}$ & .390 & .707. & - & & & & & \\
\hline 18 & $\begin{array}{l}.31 \\
9\end{array}$ & $\begin{array}{l}.33 \\
8\end{array}$ & $\begin{array}{l}.37 \\
1\end{array}$ & $\begin{array}{l}.30 \\
9\end{array}$ & $\begin{array}{l}.30 \\
7\end{array}$ & $\begin{array}{l}.41 \\
7\end{array}$ & .300 & .583 & .649 & - & & & & \\
\hline 19 & $\begin{array}{l}.31 \\
3\end{array}$ & $\begin{array}{l}.43 \\
7\end{array}$ & $\begin{array}{l}.43 \\
8\end{array}$ & $\begin{array}{l}.38 \\
4\end{array}$ & $\begin{array}{l}.40 \\
2\end{array}$ & $\begin{array}{l}.43 \\
7\end{array}$ & .364 & .596 & .710 & .752 & - & & & \\
\hline 20 & $\begin{array}{l}.40 \\
4\end{array}$ & $\begin{array}{l}.44 \\
8\end{array}$ & $\begin{array}{l}.46 \\
3\end{array}$ & $\begin{array}{l}.49 \\
8\end{array}$ & $\begin{array}{l}.35 \\
8\end{array}$ & $\begin{array}{l}.42 \\
2\end{array}$ & .365 & .583 & .610. & .657 & .691. & - & & \\
\hline 23 & $\begin{array}{l}.47 \\
1\end{array}$ & $\begin{array}{l}.43 \\
9\end{array}$ & $\begin{array}{l}.49 \\
3\end{array}$ & $\begin{array}{l}.46 \\
7\end{array}$ & $\begin{array}{l}.40 \\
1\end{array}$ & $\begin{array}{l}.50 \\
1\end{array}$ & .436 & .579 & .584 & .608 & .627 & .711 & - & \\
\hline 25 & $\begin{array}{l}.36 \\
4 \\
\end{array}$ & $\begin{array}{l}.35 \\
8 \\
\end{array}$ & $\begin{array}{l}.40 \\
4 \\
\end{array}$ & $\begin{array}{l}.31 \\
8 \\
\end{array}$ & $\begin{array}{l}.39 \\
8 \\
\end{array}$ & $\begin{array}{l}.51 \\
1 \\
\end{array}$ & .358 & .511 & .548 & .451 & .512 & .539 & .663 & \\
\hline
\end{tabular}

Note. $\mathrm{N}=305$; All inter-item correlations significant at $p<.01$. 
Table 9

Item Factor loadings, Item Means, and Standard Deviations for the GCQ

\begin{tabular}{lllll}
\hline Item \# & Task Conflict & Social Conflict & Mean & $\begin{array}{l}\text { Standard } \\
\text { Deviation }\end{array}$ \\
\hline 7 & & & 3.52 & 2.21 \\
8 & .731 & & 3.77 & 2.30 \\
9 & .740 & & 2.39 & 1.81 \\
10 & .782 & & 3.17 & 2.11 \\
11 & .855 & & 3.62 & 2.22 \\
13 & .808 & & 2.59 & 1.74 \\
15 & .706 & .750 & 4.37 & 2.10 \\
16 & .637 & .815 & 2.68 & 1.83 \\
17 & & .795 & 3.28 & 2.22 \\
18 & & .842 & 3.03 & 2.27 \\
19 & & .813 & 3.15 & 2.12 \\
20 & & .797 & 3.06 & 2.11 \\
23 & & .671 & 3.00 & 2.04 \\
25 & & 2.08 & 1.68 \\
\hline
\end{tabular}

Note. $\mathrm{N}=305$; Conflict measured on 1-9 Scale; All factor loadings significant at $p=.00$. 